\title{
Effect of Theophylline on Membrane Potential and Contractile Force in Hamster Diaphragm Muscle In Vitro
}

\author{
Sharon Esau \\ Department of Internal Medicine, University of Virginia, Charlottesville, Virginia 22908
}

\begin{abstract}
Theophylline enhances the force of diaphragmatic contraction and delays fatigue. The mechanism is not known, but recent evidence suggests it may act at the cell membrane. To test this hypothesis, we studied the effect of theophylline on resting membrane potential and tension in hamster diaphragm cells. Muscle strips were obtained from five adult hamsters and placed in Krebs solution, aerated with $95 \% \mathrm{O}_{2}, 5 \% \mathrm{CO}_{2}$. Resting membrane potential was measured using 3-M KCl-filled glass microelectrodes; 15-22 fibers in each strip were sampled. Force frequency curves (twitch to $100 \mathrm{~Hz}$ ) were obtained. The muscle bath was then changed to one containing $100 \mathrm{mg} / \mathrm{liter}(0.55)$ theophylline. Resting membrane potential was $-76 \pm 3 \mathrm{mV}$ (mean \pm S.D.) in Krebs solution and increased to $-85 \pm 3 \mathrm{mV}(P$ $<0.01$ ) with added theophylline. Tension increased from $5 \%$ (at $100 \mathrm{~Hz}$ ) to $20 \%$ (at $10 \mathrm{~Hz}$ ) with theophylline.

Hyperpolarization indicates an increase in intracellular to extracellular potassium concentration. Net potassium outflow occurs with each contraction, causing the cell membrane to become depolarized with repeated contractions, ultimately leading to fatigue. The hyperpolarization of the skeletal muscle cell membrane observed with theophylline may play an important role in prolonging time to fatigue.
\end{abstract}

\section{Introduction}

Methyl xanthines, such as theophylline, improve the contractility of fresh diaphragm muscle, delay the onset of fatigue, and hasten the recovery from fatigue $(1,2)$. These drugs are thought to affect the calcium release and/or reuptake mechanisms $(3,4)$ but the exact mechanism of action is unclear. Verapamil blocks the action of theophylline, but not caffeine (5), which raises the possibility of a cell membrane site of action for theophylline.

The resting membrane potential is largely determined by the ratio of intracellular to extracellular potassium (6). Hypokalemia has been reported in patients with theophylline overdose $(7,8)$, and appeared to be due to shifts in potassium to the intracellular space, rather than external potassium loss. If such a shift occured,

This work was presented in abstract form at the American Federation for Clinical Research, Washington, DC, May 1985.

Address reprint requests to Dr. Esau, Box 225, University of Virginia, Charlottesville, VA 22908.

Received for publication 13 August 1985.

J. Clin. Invest.

(c) The American Society for Clinical Investigation, Inc.

$0021-9738 / 86 / 02 / 0638 / 03 \$ \$ 1.00$

Volume 77, February 1986, 638-640 one would predict an increase (hyperpolarization) in resting membrane potential $\left(\mathrm{E}_{\mathrm{m}}\right){ }^{1}$ To test the hypothesis that theophylline acts to hyperpolarize skeletal muscle cell membranes, we measured $E_{m}$ in isolated perfused hamster diaphragm muscle before and after incubation with theophylline.

\section{Methods}

Diaphragm muscles were obtained from adult golden hamsters. The animals were anesthesized using $15 \mathrm{mg} / 100 \mathrm{~g}$ sodium pentobarbital injected intraperitoneally. Strips 5-7 mm wide (extending from the rib to the central tendon) were excised from the lateral costal portion of the diaphragm where the fibers are most parallel. The strips were stored in Krebs solution at $0^{\circ} \mathrm{C}$ and bubbled with $95 \% \mathrm{O}_{2} / 5 \% \mathrm{CO}_{2}$.

The control studies were done in Krebs solution $(\mathrm{Na}, 118 \mathrm{mM} ; \mathrm{KCl}$, $4.9 \mathrm{mM} ; \mathrm{CaCl}_{2}, 2.5 \mathrm{mM} ; \mathrm{MgSO}_{4}, 1.18 \mathrm{mM} ; \mathrm{KH}_{2} \mathrm{PO}_{4}, 1.18 \mathrm{mM}$; $\mathrm{NaHCO}_{3}, 25 \mathrm{mM}$; and glucose, $2 \mathrm{~g} /$ liter). The test solution was identical to the Krebs solution except for the addition of $100 \mathrm{mg} /$ liter $(0.55 \mathrm{mM})$ theophylline. Both solutions were at $37^{\circ} \mathrm{C}$ during experiments; $\mathrm{pH}$ was 7.37.

The muscle strips were first positioned in the control solution with the rib end sutured to a fixed rod with 2-0 silk thread. The central tendon was positioned under a glass rod which acted as a fulcrum, and attached to an FT03 force transducer (Grass Instrument Co., Quincy, MA) with 2-0 silk thread. The signal from the force transducer was amplified using a preamplifier (Hewlett-Packard Co., Palo Alto, CA) and displayed on an oscilloscope (Tektronix, Inc., Beaverton, OR).

Resting membrane potentials of 15-22 fibers were measured using 3-M KCl-filled glass microelectrodes (tip resistance 10-20 megohms) which were connected to an amplifier (World Precision Instruments, Inc., New Haven, CT). The signal was displayed on the oscilloscope. Satisfactory penetration was assumed to have occurred when a sudden and sustained drop in voltage was observed. The muscle length was adjusted to the length at which twitch tension was maximal. Control measurements of resting potential and tension production were made. Force frequency curves were generated by stimulating the muscle with trains of $0.2-\mathrm{ms}$ pulses at frequencies ranging from 10 to 100 pulses/s for $0.4 \mathrm{~s}$. The bath was then changed to Krebs plus theophylline solution and the above measurements were repeated after 15-20 min of equilibration.

Membrane potentials in the two solutions were compared using analysis of variance. Tension production was compared using the paired $t$ test.

\section{Results}

Data was obtained from strips from six hamster diaphragms. One strip was discarded because maximum tension was $<1.0 \mathrm{~g} /$ $\mathrm{cm}^{2}$, suggesting it was damaged. The remaining 10 strips were analyzed. Tension was increased at all frequencies in 9 of 10

1. Abbreviations used in this paper: $\mathrm{E}_{\mathrm{m}}$, resting membrane potential. 


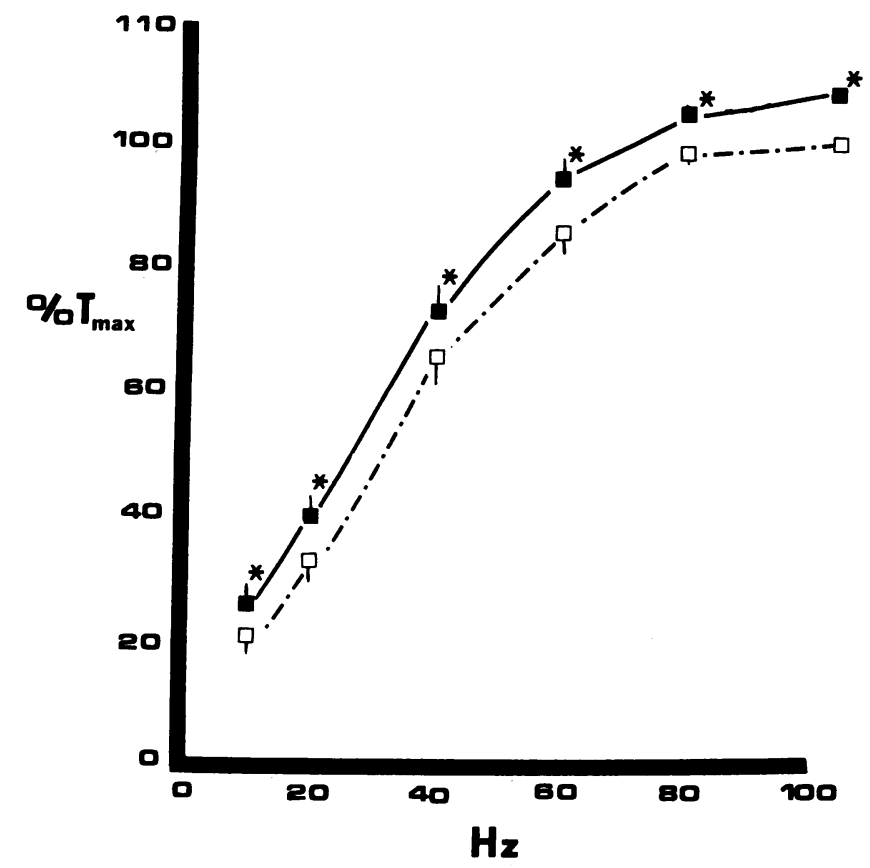

Figure 1. Force frequency relationships expressed as percent maximum tension $\left(\% T_{\max }\right)$ produced at varying frequencies of stimulation in control diaphragm strips (. -. .) compared with theophyllinetreated strips (- - ). Bars are \pm S.E. $\left({ }^{*} P<0.01\right)$ by paired $t$ test.

strips, with the largest increase at low frequency (Fig. 1). Maximum tension increased $170 \pm 20 \mathrm{~g} / \mathrm{cm}^{2}$ (mean \pm SEM) in theophylline solution compared with control $(P<0.05)$. Membrane potential was $-76 \pm 3 \mathrm{mV}$ in control solution and $-85 \pm 3 \mathrm{mV}$ in theophylline solution $(P<0.05)$. Analysis of variance confirmed no significant differences in $E_{m}$ of muscle strips within either group. Of note, in the one strip which did not increase in tension with theophylline, $\mathrm{E}_{\mathrm{m}}$ did not change either.

\section{Discussion}

This study demonstrated hyperpolarization of the hamster diaphragm membrane in the presence of theophylline $(0.55 \mathrm{mM})$. Although the dose of theophylline used was high compared with the commonly used therapeutic range $(10-20 \mu \mathrm{g} / \mathrm{ml})$, it is a small dose for in vitro work. Studies in man at blood levels of 10-13 $\mu \mathrm{g} / \mathrm{ml}$ have shown an increase in transdiaphragmatic pressure of $15 \%$ in nonfatigued states and a reversal of low frequency fatigue when given after fatigue is induced $(9,10)$. Similar increase in tension and reversal of low frequency fatigue in an in vitro preparation of human sternomastoid muscle required $1 \mathrm{mM} /$ liter, i.e., $180 \mu \mathrm{g} / \mathrm{ml}$ (11). Similarly, dose-response curves in isolated rat diaphragm required from 250 to $1000 \mu \mathrm{g} / \mathrm{ml}$ to produce increases in tension of $19-75 \%$ (12), while in in vivo studies in dogs (1) only $20-80 \mu \mathrm{g} / \mathrm{ml}$ produced the same increase in tension (12-60\%). These studies suggest that higher doses are required in the isolated preparation in vitro to achieve the same effect. This difference in drug requirements has also been noted with caffeine. While $8 \mu \mathrm{g} / \mathrm{ml}$ caffeine increased transdiaphragmatic pressure by $50 \%$ in normal human subjects (10), $18 \mu \mathrm{g} /$ $\mathrm{ml}$ in an in vitro preparation of human sternomastoid muscle increased tension $<10 \%$ (12). Our increase of $17 \%$ suggests that we were seeing an effect comparable to that seen at therapeutic levels in vivo.

Resting membrane potential is determined predominantly by the ratio of intracellular to extracellular potassium and sodium (6), as described by the Nernst equation: $E=(n R T) / F \cdot \ln \left([K]_{0} /\right.$ $\left.[K]_{i}\right)$. Slight variations in measured $E_{m}$ from that predicted by this equation are due to $\mathrm{Na}^{+}$ion activity. Our observation that theophylline hyperpolarizes the cell membrane suggests that intracellular potassium has increased. Hypokalemia has been reported in patients with theophylline overdose $(7,8)$, and has been attributed to respiratory alkalosis, or elevation of either insulin or catecholamine levels. Insulin has been noted to hyperpolarize sarcolemmal membrane (13), but the role of potassium in this phenomenon remains unclear. Neither insulin nor catecholamines were present in the bath and $\mathrm{pH}$ was controlled. Therefore it is unlikely that these factors contributed to the hyperpolarization in this study.

The precise mechanism of theophylline activity at the cellular level in skeletal muscle is unclear. Theophylline, like caffeine, increases the free intracellular $\mathrm{Ca}^{++}$; initially these drugs were both thought to be acting by increasing $\mathrm{Ca}^{++}$release from the sarcoplasmic reticulum (14). However, the potentiation of force by theophylline does not occur in the absence of external $\mathrm{Ca}^{++}$ (15) or in the presence of verapamil (5). Therefore, it appears that theophylline causes an influx of $\mathrm{Ca}^{++}$from the extracellular space. Calcium influx has not been thought to play a large role in skeletal muscle contraction. However, slow inward $\mathrm{Ca}^{++}$currents and associated slow action potentials have been demonstrated in mouse skeletal muscle (16) under specialized experimental circumstances. These $\mathrm{Ca}^{++}$currents are blocked by verapamil.

In many nerve cells there is a $\mathrm{Ca}^{++}$-induced $\mathrm{K}^{+}$current which leads to hyperpolarization of the membrane. This hyperpolarization is potentiated by theophylline (17). $\mathrm{Ca}^{++}$-dependent $\mathrm{K}^{+}$ channels have also been demonstrated in rabbit skeletal muscle T tubule membranes, but their physiologic role is not known (18). It is possible, although highly speculative, that theophylline induces an influx of $\mathrm{Ca}^{++}$, which in turn activates these $\mathrm{Ca}^{++}$. dependent $\mathrm{K}^{+}$channels and results in the hyperpolarization we observed. In support of this hypothesis we have preliminary data on the effect of verapamil and theophylline combined; with this combination hyperpolarization of the membrane does not occur (19).

Theophylline preparations have been shown to effect both contractility and fatiguability. Resting potential is an important determinant of $\mathrm{Na}^{+}$channel activation and therefore the magnitude of the action potential. As $\mathrm{E}_{\mathrm{m}}$ decreases, $\mathrm{Na}^{+}$channel activation decreases. However, since $\mathrm{Na}^{+}$channel activation is nearly maximal at usual $\mathrm{E}_{\mathrm{m}}$, it is unclear whether significant increase could occur with mild hyperpolarization.

Marked hyperpolarization may have a detrimental effect by raising the voltage change needed to reach activation threshold and thus inhibiting contraction. Moderate hyperpolarization may have a role in delaying fatigue. With repeated contractions, there is a shift of potassium from the intracellular space to $T$ tubules and other extracellular space $(20,21)$. This leads to a depolarization of the resting $E_{m}$ with a resulting diminution of action potential and failure to contract once $E_{m}$ reaches $-40 \mathrm{mV}$. The loss of potassium with each contraction is relatively constant (22). Therefore, as $E_{m}$ increases one might expect the time to fatigue to increase. Support for this hypothesis comes from observations in physically conditioned dogs (23). After several 
weeks of treadmill training, their endurance times increased from 20-100 to 36-140 min. The resting $E_{m}$ of intercostal muscles was $-87 \pm 5 \mathrm{mV}$ before training and increased to $-95 \pm 4 \mathrm{mV}$ after training. Although intracellular $\mathrm{K}^{+}$was increased, it was not sufficient to account for this degree of hyperpolarization. $\mathrm{Na}^{+}-\mathrm{K}^{+}$ATPase activity was also increased, raising the possibility that increased $\mathrm{Na}^{+}$permeability could also contribute to membrane hyperpolarization.

In summary, addition of the theophylline to the in vitro hamster diaphragm preparation was associated with hyperpolarization of the resting sarcolemmal membrane. The mechanism of this is not known, but may involve increases in intracellular potassium, possibly mediated by calcium influx. It is unlikely that the theophyllin effects were mediated by $\mathrm{pH}$, insulin, or catecholamines.

\section{Acknowledgments}

I would like to thank Dr. Dudley F. Rochester for his helpful comments and criticisms and Ms. Karen Fultz and Mrs. Suzanne Whitehurst for their assistance in preparing this manuscript.

\section{References}

1. Sigrist, S., D. Thomas, S. Howell, and C. Roussos. 1982. The effect of aminophylline on inspiratory muscle. Am. Rev. Respir. Dis. 126:4650.

2. Murciano, D., M. Aubier, Y. Lecocguic, and R. Pariente. 1984. Effects of theophylline on diaphragmatic strength and fatigue in patients with chronic obstructive pulmonary disease. N. Engl. J. Med. 311:349353.

3. Endo, M. 1975. Mechanism of action of caffeine on the sarcoplasmic reticulum of skeletal muscle. Proc. Jpn. Acad. 51:479-484.

4. Weber, A. 1968. The mechanism of action of caffeine on sarcoplasmic reticulum. J. Gen. Physiol. 52:760-765.

5. Aubier, M., D. Murciano, N. Viires, Y. Lecocguic, and R. Pariente. 1983. Diaphragmatic contractility enhanced by aminophylline: role of extracellular calcium. J. Appl. Physiol.: Respirat. Environ. Exercise Physiol. 54:460-464.

6. Hodgekins, A. L., and P. Horowitz. 1959. The influence of potassium on single muscle fibers. J. Physiol. (Lond.). 148:127-160.

7. Hall, K., K. Dobson, J. Dalton, M. Ghignone, and B. Penner. 1984. Metabolic abnormalities associated with intentional theophylline overdose. Ann. Intern Med. 101:457-462.

8. Buckley, B., R. Braithwaite, and J. Vale. 1983. Theophylline poisoning (letter). Lancet. ii:618.
9. Aubier, M., A. Detroyer, M. Sampson, P. T. Macklem, and C. Roussos. 1981. Aminophylline improves diaphragmatic contractility. $N$. Engl. J. Med. 305:249-252.

10. Supinski, G. S., E. D. Deal, and S. G. Kelsen. 1984. The effects of caffeine and theophylline on diaphragmatic contractility. Am. Rev. Resp. Dis. 130:429-433.

11. Jones, D. A., S. Howell, C. Roussos, and R. H. T. Edwards. 1982. Low frequency fatigue in isolated skeletal muscles and the effects of methylxanthines. Clin. Sci. (Lond.). 63:161-167.

12. Kentera, D., and V. M. Varagic. 1975. The effects of cyclic $N-2-$ $O$-dibutyryl-adenosine $3{ }^{\prime} 5^{\prime}$-monophosphate, adrenaline and aminophylline on the isometric contractility of the isolated hemidiaphragm of the rat. Br. J. Pharmacol. 54:375-381.

13. Zierler, K. L. 1966. Possible mechanisms of insulin action on membrane potential and ion fluxes. Am. J. Med. 40:735-739.

14. Rall, T. W. 1983. The xanthines. In The Pharmacologic Basis of Therapeutics. L. S. Goodman and A. Gilman, editors. Macmillan Publishing Co., New York. 598-607.

15. Varagic, V. M., and D. Kentera. 1978. Intercations of calcium, dibutyryl cyclic AMP, isoprenaline and aminophylline on the isometric contraction of the isolated hemidiaphragm of the rat. Naunyn-Schmiedeberg's Arch. Pharmakol. 303:47-53.

16. Kerr, L. M., and N. Sperelakis. 1983. $\mathrm{Ca}^{+2}$-dependent slow action potentials in normal and dystrophic mouse muscle. Am. J. Physiol. 245:C415-C422.

17. Busis, N. A., and F. F. Weight. 1976. Spike after-hyperpolarisation of a sympathetic neurone is calcium sensitive and is potentiated by theophylline. Nature (Lond.). 263:434-436.

18. Latorre, R., C. Vergara, and C. Hidalgo. 1982. Reconstitution in planar lipid bilayers of $\mathrm{Ca}^{+2}$-dependent $\mathrm{K}^{+}$channel from transverse tubule membranes isolated from rabbit skeletal muscle. Proc. Natl. Acad. Sci. 79:805-809.

19. Esau, S. A., and D. F. Rochester. 1985. The effect of verapamil on hamster diaphragm tension and resting membrane potential. Phy siologist. 28:321a. (Abstr.)

20. Sjogaard, G. 1983. Electrolytes in slow and fast muscle fibers of humans at rest and with dynamic exercise. Am. J. Physiol. 245:R25R31.

21. Hirche, H. J., E. Shumacker, and H. Hagemann. 1980. Extracellular $\mathrm{K}^{+}$concentration and $\mathrm{K}^{+}$balance of the gastrocnemius of the dog during exercise. Pfleugers Arch. Eur. J. Physiol. 387:231-237.

22. Hnik, P., M. Holas, I. Kreukule, N. Kriz, J. Mejsnar, V. Smiesko, E. Ujec, and F. Vyskocil. 1976. Work-induced potassium changes in skeletal muscle and effluent venous blood assessed by liquid ion-exchanger microelectrodes. Pfluegers Arch. Eur. J. Physiol. 362:85-94.

23. Knochel, J. P., J. D. Blachley, J. H. Johnson, and N. W. Carter. 1985. Muscle cell electrical hyperpolarization and reduced exercise hyperkalemia in physically conditioned dogs. J. Clin. Invest. 75:740-745. 